DOI: 10.17707/AgricultForest.62.1.05

\author{
Roberto CAPONE, Hamid EL BILALI, \\ Philipp DEBS, Francesco BOTTALICO ${ }^{I}$
}

\title{
RELATIONS BETWEEN FOOD AND NUTRITION SECURITY, DIETS AND FOOD SYSTEMS
}

\section{SUMMARY}

The food arena, which is at the interface of different economic sectors, is characterised by the presence of numerous actors with often different and even competing agendas. This is exacerbated by the lack of a deep and common understanding of the issues at play and their interdependencies. The review paper aims at highlighting the multifaceted and multidimensional relations and linkages between food and nutrition security, diets and food systems in the context of sustainability. The paper addresses also other issues, which are relevant in sustainable food systems context, such as sustainable consumption and production, typical and traditional foods, and food losses and waste. Food security is built on four pillars: availability, access, use, and stability. It is strongly linked to nutrition security. Sustainable diets are environmentallyfriendly and contribute to food security and healthy life. The Mediterranean diet, which encompasses a plethora of traditional and typical foods, is considered by many scholars as an example of sustainable diet. Food systems should deliver food security and nutrition for present and future generations that is why all components of food systems should be sustainable, resilient and efficient. Moving towards more sustainable food systems implies also reducing food losses and waste along the food chain. Sustainability should be considered as a dimension of long-term food security. From such a perspective the concept of sustainable diets can play a key role. To address food and nutrition challenges, food systems have to be considered in their entirety, acknowledging the interdependency of consumption and production. These linkages are shown in the global Zero Hunger Challenge initiative and should be highlighted and further operationalized in global food-related strategies (e.g. 10 Year Framework of Programs on Sustainable Food Systems) as well as regional strategies such as the Sustainable Consumption and Production Action Plan for the Mediterranean.

Keywords: Food and nutrition security, Sustainable diets, Mediterranean diet, Food systems

\section{INTRODUCTION}

The interactions between the diverse actors and processes in food systems are more complex than meets the eye (IPES-Food, 2015). Food system is at the

\footnotetext{
${ }^{1}$ Roberto Capone, Hamid El Bilali, Philipp Debs, Francesco Bottalico, (corresponding author: elbilali@iamb.it), Sustainable Agriculture, Food and Rural Development department; International Centre for Advanced Mediterranean Agronomic Studies in Bari (CIHEAM-Bari), Valenzano (Bari), ITALY

Paper presented at the $6^{\text {th }}$ International Scientific Agricultural Symposium "AGROSYM 2015".

Notes: The authors declare that they have no conflicts of interest. Authorship Form signed online.
} 
interface of different economic sectors. The food arena is characterised by the presence of numerous actors with often different and even competing and contradictory agendas (Hopkins et al., 1982). This is exacerbated by the lack of a common understanding of the interdependencies of food-related issues at play. From persistent undernutrition to burgeoning obesity rates, from land evictions to agricul $\neg$ ture's soaring environmental footprint, from dwindling fish stocks to mounting food waste, there has rarely been so much attention on the problems within food systems. However, there has been a tendency among scientists and policymakers to address the problems as individual pieces of the puzzle, and to over-look their interrelations (IPES-Food, 2015).

Realizing development and sustainability goals such as the reduction of hunger and poverty and the improvement of rural livelihoods and human health requires acknowledging the multifunctionality of agriculture and food sector. The challenge is to simultaneously meet development and sustainability while increasing agricultural production (IAASTD, 2009).

Unsustainable food consumption patterns are putting increasing stress on ecosystems, the supply of resources, goods and services, and human social systems and well-being. Food consumption and production patterns are among the most important drivers of environmental pressures (e.g. land degradation, declining soil fertility, unsustainable water use). The social and economic costs of diet-related illnesses are straining individuals, families and national healthcare budgets.

FAO (2012) pointed out that ending hunger requires that food consumption and production systems achieve more with less resources which encompasses fostering sustainable intensification of food production, encouraging sustainable food consumption and reducing food losses and waste. Drivers for consumption patterns and lifestyles are economic, technological, cultural, social and political. Sustainable food consumption is a powerful driver to reduce ecological scarcities and improve social equity. It involves harnessing global demand by promoting more sustainable diets.

The present review paper aims at highlighting relations and linkages between food and nutrition security, diets and food systems. The paper addresses also other issues such as sustainable consumption and production, Mediterranean diet, typical and traditional agro-food products and food losses and waste, which are relevant in the context of sustainable food systems. The ultimate aim is to see how sustainable diets can help developing sustainable food systems and achieving food and nutrition security.

\section{RESULTS AND DISCUSSION}

Food security exists when all people at all times have physical, social and economic access to sufficient, safe and nutritious food. Food and nutrition security embraces meeting energy, protein and nutrient needs for healthy life (CFS, 2012). The Rome Declaration on World Food Security in 1996 defined its three basic dimensions as: availability, accessibility and utilization. In 2009, at 
the World Summit on Food Security, the dimension of stability/vulnerability was added (Berry et al., 2014). Therefore, food security is built on four pillars (CFS, 2012; UN-HLTF, 2011; Ericksen, 2011): food availability: sufficient quantities of food available on a consistent basis; food access: having sufficient resources to obtain appropriate foods for a nutritious diet; food use: appropriate use based on knowledge of basic nutrition and care; and stability in food availability, access and utilization.

Food security is a problem from the individual to the global level: it is an individual issue; yet policies deal with it mostly at the national level, and it is measured at best at the household level. The existence of food security in a nation necessitates that all four interrelated and interdependent dimensions are present (Berry et al., 2014). Food security is a complex sustainable development issue. Ensuring that sufficient nutritious foods are available to all people and that they can access these foods at all times are critical elements of economic and social development.

A comprehensive approach for tackling the issue of food and nutrition security requires: (i) taking into account the interconnectedness and interactions between the food and nutrition security dimensions (availability, access, utilization and stability); (ii) addressing the full spectrum of food and nutrition security, including food production, sourcing and distribution; and (iii) ensuring multi-sectoral engagement and coordination of sectoral policies (e.g. agriculture, trade, health, education, nutrition) (UN-HLTF, 2011).

Food production and its physical availability are certainly essential to addressing hunger. However, producing more food alone will not be sufficient to achieve food and nutritional security. In fact, food and nutrition security is about more than just producing sufficient food as it encompasses the need to ensure access to food at all times. Achieving sustainable food security requires transition towards more sustainable food consumption patterns and diets and working on both sides of the food chain i.e. food production and food consumption. The focus on sustainable diets integrated in a wider food system (Fig. 1) is original in this sense and allows grasping the different facets and dimensions of food and nutrition insecurity (Capone et al., 2014).

Modern agro-food systems failed to resolve the problem of food insecurity. While the world currently produces enough food for its citizens, about 795 million people are undernourished (FAO, IFAD and WFP; 2015) while 1.4 billion are overweight or obese. Micronutrient malnutrition, often referred to as "hidden hunger", affects approximately 2 billion people worldwide, more than one third of the global population. Food insecurity and malnutrition (undernutrition, overnutrition, and micronutrient malnutrition) problems are widespread. These as well as the social, economic and environmental impacts of the current food consumption patterns and diets highlight the inadequacy of the global food system (Capone et al., 2014). 


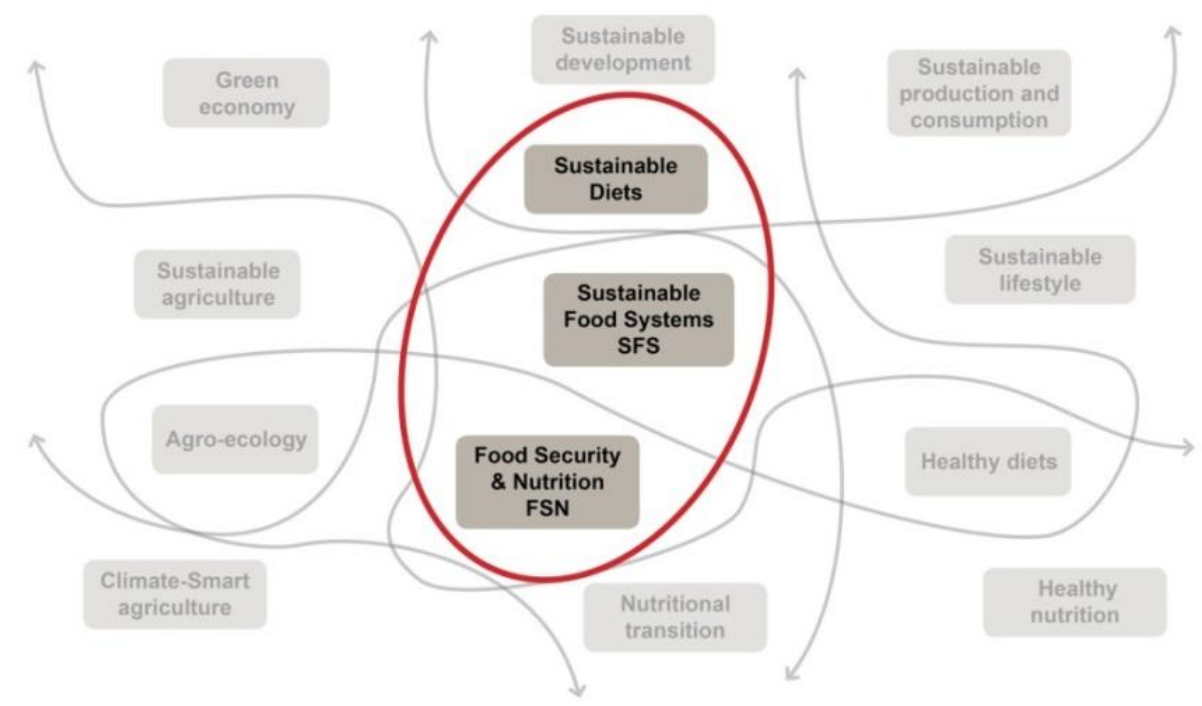

Figure 1. Sustainable diets in the contexts of sustainable food systems and food security and nutrition (Source: Gitz, 2014).

Food systems have to be considered in their entirety, acknowledging the interdependency of sustainable consumption and production. An analytical lens is needed in order to understand the various problems in food sys $\neg$ tems as the component parts of wider system-ic problems (IPES-Food, 2015). In July 2014 the High Level Panel of Experts on Food Security and Nutrition (HLPE) provided the following definition for a food system: "A food system gathers all the elements (environment, people, inputs, processes, infrastructures, institutions, etc.) and activities that relate to the production, processing, distribution, preparation and consumption of food and the outputs of these activities, including socio-economic and environmental outcomes". Food systems overlap with agricultural systems in the area of food production, but also comprise the diverse set of institutions, technologies and practices that govern the way food is marketed, processed, transported, accessed and consumed (Ericksen, 2011).

Food systems also refer to the vast web of sectoral policies and regulatory frameworks (e.g. agriculture, environment, health and safety, trade, energy, etc.) that shape food systems as they interact with one another (IPES-Food, 2015). Previous policies and actions fell short from addressing the problem of food and nutrition security. In fact, most of the previous strategies focused on food availability - adopting a quantitative approach aiming at increasing agricultural production - while little attention has been devoted to the other components of food and nutrition security mainly food accessibility and food utilisation. The challenge of feeding the growing world population requires new strategies and approaches (Capone et al., 2014). 
To address food and nutrition challenges, food systems have to undergo radical transformation for improving resource efficiency, improving equity and transitioning towards sustainable diets. According to FAO \& Bioversity (2012) "Sustainable diets are those diets with low environmental impacts which contribute to food and nutrition security and to healthy life for present and future generations. Sustainable diets are protective and respectful of biodiversity and ecosystems, culturally acceptable, accessible, economically fair and affordable; nutritionally adequate, safe and healthy; while optimizing natural and human resources". Transformation of food systems towards sustainable diets is an essential part of sustainable development. It offers vast economic and social opportunities, while preserving natural resources.

Changes in patterns of food production and consumption force to rethink agricultural systems and diets. Simplification of diets led to diets low in variety but high in energy that do not solve the problems of undernutrition and micronutrient deficiencies but also promote obesity and chronic diseases. A sustainable diets approach aims to address nutrition requirements, both in terms of energy and nutriments and resources used for food production, including local biodiversity, used to produce traditional and local foods. Traditional and typical foods represent the opposite of mass food production. They date back to before the large-scale alteration of traditional food production processes. Traditional foods can be at the epicentre of the effort to preserve diversity and collective identity. Communities and cultures that maintain their own traditional food systems are better able to conserve local food specialties with a corresponding crop and animal diversity (Trichopoulou, 2012). The Mediterranean diet offers a clear example.

The Mediterranean diet (MD), which encompasses a plethora of traditional and typical foods, is currently studied by CIHEAM and FAO as a case study for the assessment of the sustainability of dietary patterns in the Mediterranean area (Lacirignola et al., 2012). The Mediterranean diet, recognized by the World Health Organisation (WHO) as a healthy eating pattern and included in 2010 in the UNESCO's List of Intangible Cultural Heritage of Humanity, represents a valid tool for promoting more sustainable consumption and production patterns.

The MD has been reported as a model of healthy eating. A greater adherence to it has been associated with significant health, nutrition and environmental benefits. People adhering to the Mediterranean dietary patterns comply better with recommended nutrient and micronutrient intakes. Different studies have confirmed the beneficial role of the MD with regard to mortality from all causes including cardiovascular diseases (CVD) and cancer, as well as obesity, type 2 diabetes and degenerative diseases. The Mediterranean dietary pattern (MDP) has also low environmental footprints and contributes to reducing biodiversity loss. The MDP can also effectively contribute to the worldwide efforts for climate change mitigation as it encompasses lower carbon footprints i.e. greenhouse gas emissions. Therefore, it should be promoted as a cornerstone in public health and sustainable consumption strategies. Unfortunately, there is 
an ongoing decrease of adherence to the Mediterranean dietary pattern (CIHEAM \& FAO, 2015).

Agriculture, food security, nutrition and sustainability are increasingly discussed in the same context (Lang, 2009). More recently, intergovernmental processes have emphasized the importance of food security as part of sustainability and vice-versa (Berry et al., 2014). There are very strong linkages between food and nutrition security, and food sustainability. They intersect in agricultural and food systems at the global, national and local levels. A sustainable food system supports food security. Food and nutrition security is a cornerstone of sustainable diets and food consumption patterns (Capone et al., 2014). According to Garnett (2013), broadly three perspectives are emerging on how to achieve sustainable food security and food system sustainability: efficiency oriented, demand restraint and food system transformation.

According to the HLPE (2014) "A sustainable food system (SFS) is a food system that delivers food security and nutrition for all in such a way that the economic, social and environmental bases to generate food security and nutrition for future generations are not compromised". The unsustainability of food systems is the main reason for the existence of food insecurity and malnutrition; if food systems do not perform adequately in their environmental, economic and social dimensions, food security and nutrition are threatened. For ensuring food security and nutrition all components of food systems should be sustainable, resilient and efficient.

The unique opportunity to make agriculture and food systems more sustainable should not be missed. The primary objective of agriculture is to produce enough food to feed 9 or 10 billion people by 2050 . This largely needs to be accomplished by crop and animal productivity increases as well as reducing food losses and waste and changing diets, always keeping in mind that the Earth's natural resource base is finite. Aspirations of maximum consumption should be replaced by patterns of optimized consumption (Capone et al., 2014).

About a third of the global food production is lost or wasted with severe impacts on the world's economy and environment (Gustavsson et al., 2011). Food losses and waste prevention and reduction would allow meeting the food needs of about one billion undernourished people. Reducing post-harvest losses and food waste - by using the available knowledge and technologies, education campaigns and adopting innovative legal frameworks - would reduce waste and ease the pressure on agro-ecological systems to meet the growing food demand, thus, contributing to improving food systems sustainability and ensuring food security and nutrition.

Any future initiative on food and nutrition security should embrace the sustainability paradigm and involve all the relevant actors along the food chain, create linkages with the existing global and regional multi-stakeholder processes and develop a multi-faceted research agenda. Research activities are needed to analyse the sustainability of the current dietary patterns in order to design 
appropriate policy actions and measures (Capone et al., 2014; CIHEAM \& FAO, 2015).

Sustainability can be considered as a precondition for long-term food security. The environment, climate and the obtainability of natural resources, are a precondition for the availability of food. Economic and social sustainability are necessary for the accessibility of all to food. Social sustainability is also a determinant for the utilization of food. Together, the three dimensions of sustainability - social and economic and environmental - also ensure the stability of the systems on which depends the constancy of the other dimensions of food security. On the other hand, food security is considered increasingly as a condition for sustainability (Fig. 2) (Berry et al., 2014).

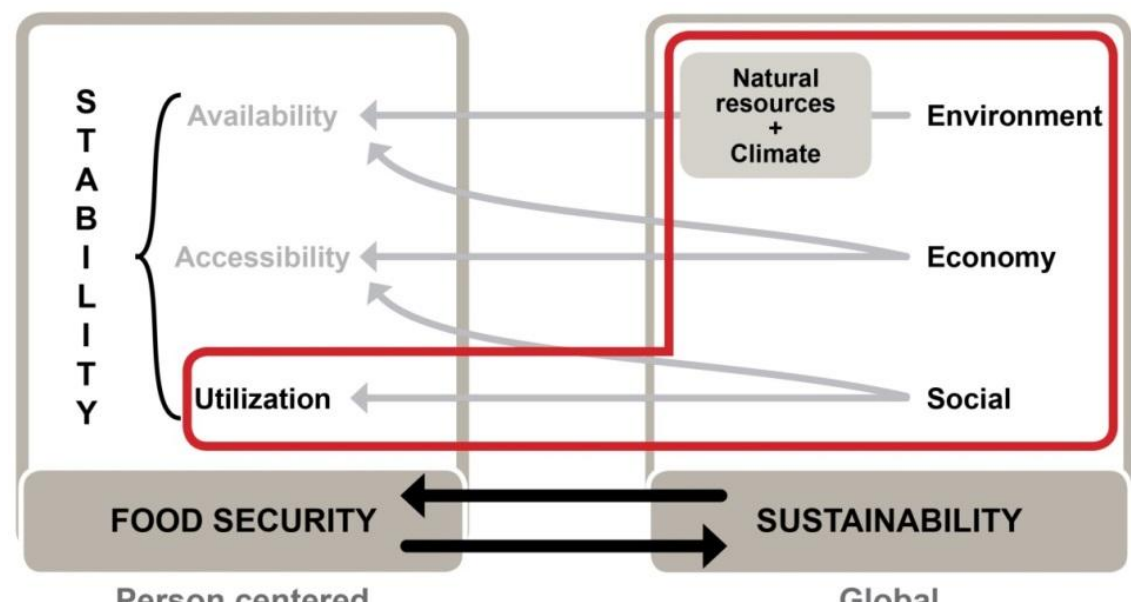

Figure 2. Linkages and interrelationships between food security and food systems sustainability (Source: Gitz, 2014; Berry et al., 2014).

Sustainability is a general concept applicable across all food security dimensions. Inclusion of sustainability recognizes that continued healthy wellbeing is the goal of sustainable food security (fig. 3) (berry et al., 2014). Sustainability should be regarded as an integral part of food security planning, monitoring and evaluation in determining the long-term viability of food system chains (searchinger et al., 2013). However, getting the concept of sustainability on the political agenda is a challenge as, in fact, the integration of food security as an explicit part of the sustainability agenda would go a long way towards such a goal. The task ahead is to build food security on sustainability and vice-versa (tilman \& clark, 2014). The final common pathway of all these efforts is towards sustainable food security and nutrition (berry et al., 2014).

Sustainability should be considered as part of the long-term time dimension in the assessment of food security. From such a perspective, the concept of sustainable diets can play a key role as a goal and a way of maintaining nutritional well-being and health while ensuring the sustainability 
for future food security. Without integrating sustainability as an explicit dimension of food security, today's policies and programmes could become the very cause of increased food insecurity in the future (berry et al., 2014). Sustainability must serve as the benchmark for food systems reform, and to do so, it must be defined at the appropriate scales. Sustainability must also be defined in all of its dimensions, in line with the emerging defini-tion of sustainable diets (ipes-food, 2015).

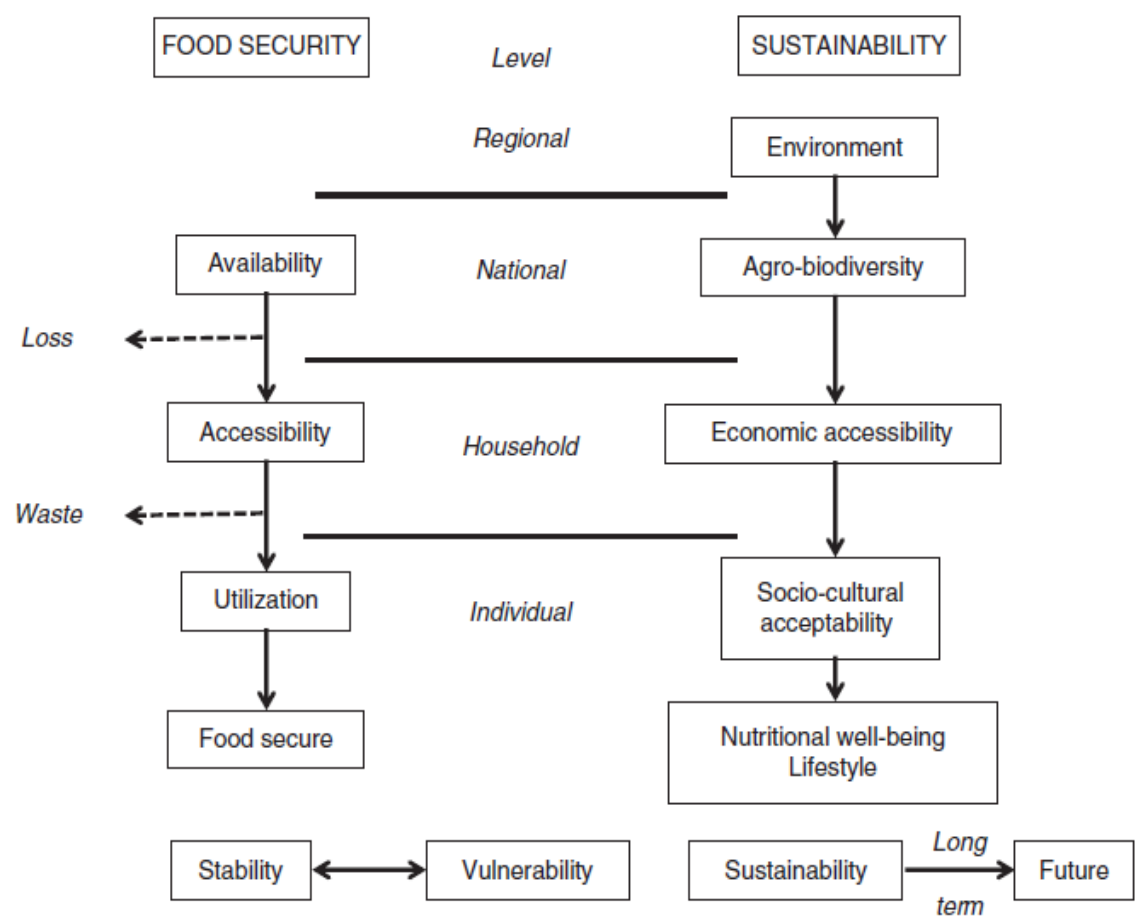

Fig. 3. The time dimension to food security: short-term stability (left) and long-term sustainability (right) (Source: Berry et al., 2014)

\section{CONCLUSIONS}

The Mediterranean region is passing through a "nutrition transition" in which problems of under-nutrition coexist with overweight, obesity and foodrelated chronic diseases. This nutrition transition is alarming as it has negative impacts on health systems. Therefore, changes in both food consumption and food production are necessary to ensure more sustainable food systems and to achieve food and nutrition security in the Mediterranean region. Since diets sustainability is crucial for achieving food and nutrition security, there is an urgent need to design and implement appropriate policies to improve the sustainability of the current food consumption patterns. Transition towards sustainable food systems in the Mediterranean area requires developing a set of comprehensive, coherent, integrated and holistic policies that deal with the 
different food-related spheres and arenas. Coordinated actions are needed at local, national and regional level with the support of the private sector and the civil society, for fostering sustainable food systems by improving the sustainability of diets and food consumption patterns. The Mediterranean diet can be regarded as a model for validating methods, metrics and indicators for sustainable diets.

Relations and linkages between food and nutrition security, diets and food systems are shown in the Millennium Development Goals (MDGs) as well as the Zero Hunger Challenge initiative of the United Nations' Secretary General. They should be highlighted and further operationalized in global food-related strategies (e.g. 10 Year Framework of Programs on Sustainable Food Systems, Sustainable Development Goals) as well as regional strategies such as the Mediterranean Strategy for Sustainable Development and the Sustainable Consumption and Production Action Plan for the Mediterranean.

\section{REFERENCES}

Barthel S., Crumley C.L. \& Svedin U. (2013). Biocultural refugia: combating the erosion of diversity in landscapes of food production. Ecol Soc, 18, 71.

Berry E.M., Dernini S., Burlingame B., Meybeck A., Conforti P. (2014). Food security and sustainability: can one exist without the other? Public Health Nutrition, pp: 110. DOI:10.1017/S136898001500021X.

Capone R., El Bilali H., Debs Ph., Cardone G., Driouech N. (2014). Food system sustainability and food security: connecting the dots. Journal of Food Security, 2(1), 13-22. DOI: 10.12691/jfs-2-1-2.

CFS (2012). Coming to terms with terminology: Food security, Nutrition security, Food security and nutrition, Food and nutrition security. Committee on World Food Security (CFS), Thirty-ninth Session, Rome; 15-20 October, 2012.

CIHEAM \& FAO (2015). Mediterranean food consumption patterns: diet, environment, society, economy and health. A White Paper of Priority 5 of Feeding Knowledge Program, Expo Milan 2015. CIHEAM-IAMB, Bari \& FAO, Rome.

Ericksen, P.J. (2008). Conceptualizing food systems for global environmental change research. Global Environmental Change, 18 (1), 234-245.

FAO \& Bioversity (2012). Sustainable Diets and Biodiversity. Directions and Solutions for Policy, Research and Action. Rome. Available at: http://www.fao.org/docrep/016/i3004e/i3004e00.htm

FAO (2012). Towards the Future We Want: End hunger and make the transition to sustainable agricultural and food systems. FAO, Rome. Available online at: http://www.fao.org/docrep/015/an894e/an894e00.pdf

FAO, IFAD and WFP (2015). The State of Food Insecurity in the World 2015. Meeting the 2015 international hunger targets: taking stock of uneven progress. FAO, Rome. 
Garnett T. (2013). Three perspectives on sustainable food security: efficiency, demand restraint, food system transformation. What role for LCA? Journal of Cleaner Production (2013), 1-9. http://dx.doi.org/10.1016/j.jclepro.2013.07.045.

Gitz V. (2014). Sustainable diets and sustainable food systems: Challenges to assess sustainable diets as a driver towards more sustainable food systems. Presentation; International Workshop on Assessing Sustainable Diets within the Sustainability of Food Systems; 15-16 September, 2014; Rome.

Gustavsson J., Cederberg C., Sonesson U., van Otterdijk R. and Meybeck A. (2011). Global food losses and food waste: extent, causes and prevention. FAO, Rome.

HLPE (2014). Food Losses and Waste in the Context of Sustainable Food Systems. HLPE, Rome. Available at: http://www.fao.org/3/a-i3901e.pdf

Hopkins R.F., Paarlberg R.L., Wallerstein M.B. (1982). Food in the global arena: Actors, values, policies and Futures. Holt, Rinehart, and Winston. Available at: http://uonlibrary.uonbi.ac.ke/content/food-global-arena-actors-values-policiesandfutures

IAASTD (2009). Agriculture at a crossroads. International assessment of agricultural knowledge, science and technology for development (IAASTD). Island Press, Washington DC.

IPES-Food (2015). The New Science of Sustainable Food Systems: Overcoming Barriers to Food Systems Reform. International Panel of Experts on Sustainable Food Systems (IPES-Food). Available at: http://www.ipesfood.org/images/Reports/IPES_report01_1505_web_br_pages.pdf

Lacirignola C., Dernini S., Capone R., Meybeck A., Burlingame B., Gitz V., El Bilali H., Debs Ph., Belsanti V. (2012). Towards the development of guidelines for improving the sustainability of diets and food consumption patterns: the Mediterranean Diet as a pilot study. CIHEAM/FAO - Options Méditerranéennes, Series B: Studies and Research, $\mathrm{N}^{\circ}$ 70; Bari. Available at: http://om.ciheam.org/om/pdf/b70 (en)/b70 (en).pdf

Lang T. (2009). Food Security and Sustainability: The Perfect Fit. Sustainable Development Commission, London.

Searchinger T., Hanson C., Ranganathan J., Lipinski B., Waite R., Winterbottom R., Dinshaw A., Heimlich R. (2013). Creating a Sustainable Future: A Menu of Solutions to Sustainably Feed More than 9 Billion People by 2050. World Resources Institute, Washington DC.

Tilman D. \& Clark M. (2014). Global diets link environmental sustainability and human health. Nature, 515, 518-522.

Trichopoulou A. (2012). Diversity v. globalization: traditional foods at the epicenter. Public Health Nutrition, 15(6): 951-954. DOI:10.1017/S1368980012000304.

UN-HLTF (2011). Food and Nutrition Security: Comprehensive Framework for Action. Summary of the Updated Comprehensive Framework for Action (UCFA). United Nations System High Level Task Force on Global Food Security (HLTF); Rome/ Genève/ New York. 